Health economists are concerned with the organization of the market for health services and the net yield of investment in people for health. The "optimum" use of resources for the care of the sick and the promotion of health defines the special field of inquiry.

\title{
Toward a Definition of Health Economics
}

\author{
SELMA J. MUSHKIN, Ph.D.
}

$\mathrm{T}$ WO RECENT developments, each traceable to scientific advances in medicine, have focused attention on nealth economics.

First, new therapeutic products have provided specifics for many infectious diseases that, less than 20 years ago, were important causes of death in the United States and other industrial nations. These changes in medical techniques, which have increased the physician's capacity to deal effectively with diseases, have altered patterns in the organization of health services. Concomitantly, problems associated with the costs of medical care have been intensified and have stimulated prepayment arrangements for meeting these costs.

These changes have also given rise to many questions about the nature of the "market" for health services; about the relation of plant "capacity" (hospital facilities, for example) to use of health services; and about variations in "demand" attributable to prepayment. Especially urgent are questions about shifts in "demand" due to third party payments for limited types of medical care and about effects of alternative methods of payment and compensation on the "price" of health services. These questions are illustrative of the many raised by altered patterns in the organization of health

Dr. Mushkin is an economist in the Division of Public Health Methods, Public Health Service, and research associate, Johns Hopkins University School of Hygiene and Public Health. services and altered methods of paying for health care. They comprise one set of economic issues.

A second set of issues arises from another development in medical science: the possibility of increasing life expectancy. Average life expectancy at birth in many of the nations of Asia and Africa-nations which include almost two-thirds of the world population - was until recently about 30 years. This may be contrasted with almost 70 years of life expectancy achieved in the United States. The potential increase in life expectancy sharply focuses problems of balance between population and resources, between work forces and output, in the industrially underdeveloped but densely populated nations of the world. Scientific advances in medicine and public health can be applied quickly and with minimum expenditures to reduce death and morbidity rates in these nations. Spraying with DDT, immunization with $\mathrm{BCG}$, and treatment with penicillin have yielded dramatic results in reduced mortality from malaria, tuberculosis, syphilis, and yaws.

Reduced death rate has intensified a search for answers to specific economic questions so that the achievements in health will not be dissipated by the pressures of increased population on low food supplies, with the consequent intensification of poverty. Some of these questions are related to the means by which the net yield of investment in people for health may 
be measured, the relative amounts of complementary and supporting capital investment and capital growth required, and the effects of changes in health status on productivity. At the same time, the changing monetary value of man, in his productive capacities, effects an impact on economic growth.

These two sets of issues in common require, among other things, an analysis of the optimum use of resources for maintaining and improving the people's health and the quality of the population. Both sets of issues have been pressed by the requirements for policy formulation-public for health issues facing less developed nations, and largely private for health issues arising out of the medical market, at least within the United States.

\section{Administrative Definition}

What then is health economics? Generally, "health economics" has been used by health administrators to refer to any investigation that deals with money in its relationship to health. The two medical journals with economics in their titles perhaps give a clue to what those in the health professions consider to be encompassed within the scope of a health economics inquiry. One of these journals, Medical Economics, is essentially a business journal for physicians, and regularly features articles on physicians' office methods and finances. Special feature articles in 1957, for example, deal with the physicians' income, hours of practice, specialties, fee determination, voluntary health insurance developments as they bear on the physicians' practice and finances, cost of practice including malpractice insurance, taxation problems such as definitions of business expense, and problems of estate planning.

The second periodical, Public Health Economics, published by the Bureau of Public Health Economics of the University of Michigan's School of Public Health, abridges articles and news items. Materials abridged are classified currently in the following manner: legislation, governmental programs in operation (Federal and State), prepayment plans, health personnel, hospital and other health facilities, receipt of care, and developments in other countries. The first issues of this pe- riodical in 1944 published news items on governmental health programs, views of the health professions on the organization and financing of health services, medical education, hospital organization and services, dental health needs and services, voluntary health insurance plans, and public health education. In the foreword to the first issues, Dr. Sinai stated, “. . . this publication is a tangible tribute to ... contributions toward the development of a new and vital blending of the medical and the social sciences. The blend is public health economics."

Thus "health economics" has been both broadly conceived to encompass the range of social sciences, including public administration, and narrowly conceived to deal with business methods of organization and of payment.

\section{Economic Propositions}

What has the professional economist had to say about health economics? Until fairly recently, economists have given little thought to the market organization of health services or to the net economic yield of investment in the health of people. This lack of attention to the medical market may be traced to the special characteristics of medicine that mark it as an exception to economic propositions that explain the mechanisms of the market generally.

There are several important characteristics of the medical market that differentiate it from the market of classical economics. First, the profit motive is not adequate as an explanation of the activity in the medical "market." Hospitàl care throughout the centuries has been either primarily public or under the auspices of nonprofit institutions. While services of physicians in the United States are organized on as individualistic basis as any profession or enterprise (and it is fair to say, even more so), physicians have accepted their social role in the community and have often cared for the sick and promoted health without remuneration for their time and skill. Also, professional motivation in pursuing the medically interesting case often causes the medical practitioner to evaluate his leisure, income, and work differently from, say, skilled operatives in industry.

Second, in medicine, price is not the sole 
means by which demand and supply of medical and health services may be equated. As a social responsibility, private associations, nonprofit in form, and private practitioners have provided necessary services for those unable to pay. And fees for services have been graded in accord with rough evaluations of ability to pay. In the economy generally, however, the price system is the instrument for the allocation of goods among consumers and their competing demands. Government traditionally has been looked upon as an instrument to correct the market mechanism where it fails markedly to satisfy the wants of individuals. In the sphere of medical care, however, individual needs have been met historically, at least in part, by nonprofit organizations and by the practitioner guided by the code of Hippocrates.

Moreover, a competitive price has been generally absent from the medical market, at least until recently. In part, this is attributable to the absence of a homogeneous commodity. Skill and capacity vary with the individual abilities of health personnel, and needs of patients differ, too.

Third, medical services are personal services; money cannot veil the transaction. The cold impersonality of money, so much a part of all other "business" transactions, is largely absent from medical exchanges between those who give services and those who receive them. For a part of what one buys in medical services is a personal relationship.

Fourth, consumers do not choose between health services and other goods and services by means of a simple rational weighing of choices, for (taking consumer health expenditures as a guide) the consumer prefers to avoid, or remove the circumstances that compel, using resources for health purposes. In every income group there is a heavy concentration of expenditures for medical care among those families who suffer illness. This concentration suggests that consumer outlays are undertaken primarily to cure or provide services for the sick. This pattern of consumer preferences may be illustrated in other ways. For example, in any year, only about one-third of the population purchases dental services (1). About one-fifth of physician services are for preventive health services; the remaining serv- ices are for the cure and diagnosis of disease (2). Moreover, data on expenditures and on the relation of expenditure to income suggest that the familial patterns of consumption are distorted when illness strikes.

Efficient organization of economic resources for health, guided by the consumer's preference, depends upon the consumer's knowledge and the extent of his education. Despite persistent efforts to educate consumers they reveal considerable absence of accurate knowledge about the quantity and quality of health services required. The nature of the medical service itself and its intangible character reinforce the-consumer's lack of knowledge about his purchaseş, and impede a rational choice that could guide the allocation of resources.

Furthermore, in an individual's purchase of many medical services, there is a social utility. Purchase of health services for the prevention of contagious and infectious diseases, such as smallpox, poliomyelitis, and whooping cough, provides a utility, or a benefit, for the community as a whole. Even curative health services, such as those for the treatment of tuberculosis or syphilis, help to prevent the spread of the diseases; thus an individual's purchase of services for his own cure benefits his neighbor. These important "extra-buyer benefits," or "external economies" in the prevention of disease, are instances in which individual demand and market price underestimate the marginal and total benefits provided. Preventive health services would be undervalued, underpriced, and underproduced, unless administrative agencies (government or nonprofit) entered the market.

\section{Population and Resources}

While economists have devoted little attention to the medical market they have long dealt with population growth in relation to limited physical resources. Malthus' Essay on the Principle of Population, first published in 1798, triggered a series of economic postulates giving a managainst-nature view which earned economics its designation as the dismal science. Most important of these postulates for health programing was the iron law of wages.

Alfred Marshall, whose Principles (written in the decade 1881 to 1890 ) represents a transi- 
tion from classical to modern economics, wrote: “. . . earlier economists argued as though man's character and efficiency were to be regarded as a fixed quantity. . . . [Economics] is getting to pay every year a greater attention to the pliability of human nature, and to the way in which the character of man affects and is affected by the prevalent methods of the production, distribution and consumption of wealth" $(3 a)$.

Marshall, dealing with the agents of production in book 4 of his Principles, considers not only the growth of the population but the health and strength of the population. Marshall opened a chapter of this book with, "We have next to consider the conditions on which depend health and strength, physical, mental and moral. They are the basis of industrial efficiency, on which the production of material wealth depends; while conversely the chief importance of material wealth lies in the fact that, when wisely used, it increases the health and strength, physical, mental and moral of the human race" $(3 b)$.

While some few economists have recognized the concept of "personal capital," of personal hazards to workers in industry as "social costs," and of health (physical and mental) as a component of workers' efficiency, by and large these concepts have been qualifications rather than integral parts of their economic propositions.

Three interrelated facets of analysis are essentially involved. Population pressures on resources, constituting one facet, have been dealt with in economic discussions of underdeveloped areas of the world (4). The Malthusian theory has gained new importance in this context.

The second facet is the capital value of man. Dublin and Lotka, demographers and actuaries rather than economists, have contributed the major work on the methodology of evaluating the capital represented by man (5). For their purpose they define capital value as the present and discounted value of future earning power of the wage earner, reduced by the costs of birth, upbringing, and maintenance during a working life. In their study they traced the thinking on man's capital value through the works of Sir William Petty, Adam Smith, William Farr, Frederick Engel, Alfred
Marshall, Irving Fisher, and others. Subsequent studies of special importance to this particular analysis are those made by Wolfbein and Wool for the U.S. Department of Labor on the measurement of a working life $(6,7)$.

The third facet is the application of costbenefit ratios to health programs. Work in this area has been traced to the 16th century study of Jean Bodin, to Richard Cantillion's essay on The Nature of Commerce in General published in 1755, and to Quetelet, a social statistician, who wrote in 1835 : "In his early years, man lives at the expense of society; he contracts a debt which he must one day discharge; and if he dies before he has succeeded in doing so, his life will have been a burden rather than a benefit to his fellow citizens ..." (8). Economic studies of cost-benefit ratios of health programs have been carried out largely by health administrators and others in the health professions rather than by economists. Hermann M. Biggs expressed the health administrator's concern in his slogan coined more than three and a half decades ago for the New York City Health Department: "Public health is purchasable; within natural limitations a community can determine its own death rate."

\section{Winslow-Myrdal Exchange}

Health cost-benefit analysis has gained new significance since World War II, especially in the studies and activities of international organizations. Major contributions to $t h$ is analysis were made by C.-E. A. Winslow in his 1951 volume on The Cost of Sickness and the Price of Health, by the exchange of views between Winslow and Gunnar Myrdal before the Fifth World Health Assembly of the World Health Organization in 1952, and in the subsequent volume by Myrdal on Economic Theory and Underdeveloped Regions published in 1957.

Differences between Winslow's views and those of Myrdal are largely differences in emphasis. Winslow argued that investment in health promised large dividends in life capital. For in the less-developed areas of the world where there was no surplus to invest in the profitable enterprise of health, the vicious cycle 
of poverty and disease pursued its course unchecked. "Men and women were sick because they were poor; they became poorer because they were sick, and sicker because they were poorer" $(9 a)$. The doctrine that successful health programs will increase the sum of human misery, Winslow said, is founded on the fallacious assumption that there is some basic law limiting economic development to that which has at the moment been realized. He pointed to improvements in agricultural production in the less developed areas of the world, to the development of mineral resources, to other social as well as economic measures improving the well-being of the population, and to the supplementation of these measures by efforts in some countries to limit excessive rates of population increases. He emphasized that the public health programs cannot be planned in a vacuum, but only as a vital part of a broader program of social improvement $(9 b, 10)$. He urged health leaders to "keep careful records of the cost of their health programmes and of the actual results attained, and make estimates of the economic gains corresponding to the decreases recorded in mortality and morbidity" (11).

Myrdal, starting from Winslow's thesis of a "vicious cycle," elaborates a theory of circular causation. In brief the Myrdal theory is that at one point of time there is accommodation in society between opposing forces. If either of two opposing forces changes, Myrdal writes, a change is bound to occur in the other force, "and start a cumulative process of mutual interaction in which the change in one factor would continuously be supported by the reaction of the other factor and so on in a circular way. ... The point is not simply that many forces are working in the same direction. They are, in fact, not doing so. In general there are periods when opposing forces balance one another so that the system remains in rest until a push or a pull is applied at one point or another. When the whole system starts moving after such a shock the changes in the forces work in the same direction, which is something different. And this is so because the variables are so interlocked in circular causation that a change in any one induces the others to change in such a way that these secondary changes support the first change, with similar tertiary effects upon the variable first affected, and so on" (12). Myrdal notes that if his theory of cumulative causation is valid, an upward movement of the entire system could be caused by pressures applied to one or several points in the system. However, in agreement with Winslow, he argues that rational policy should not induce a change in only one factor, especially with sudden or great force.

Drawing on his theory of cumulative causation, Myrdal argues that it is far from a simple matter to define or to measure the economic value of programs directed to the promotion of a population's health.

Costs and benefíts are likely to be different in the short run from what they would be otherwise and to be different in different environments. Long-run values depend on the interrelationship of factors in any given society.

Myrdal emphasized that the success of health programs will depend entirely on whether they are appropriately integrated in a program of general economic development. $\mathrm{He}$ thus agreed with Winslow that health programs should "be a vital part of a broader program of social reconstruction."

Myrdal also agreed with Winslow that a health program could increase the number of persons in the productive age groups and their productivity. But, he emphasized, "the economic value of preventing premature death ... depends entirely upon whether such an economic development is under way which ensures productive work for the greater number of people we thus keep alive" (13). If death rates are reduced in areas in which there is already substantial unemployment, poverty could be aggravated. While Myrdal, in common with Winslow, questioned the static notion of a "population optimum," in view of the expandability of production resources, he laid far greater emphasis than Winslow on the need for capital investment in production facilities. The amount of planned capacity required to prevent economic stagnation and increased distress would be enlarged by a truly successful health program.

Myrdal suggested that calculations on the price of health and the cost of illness should be based on something other than a dollar value of people. 
Success of a program, for example, might be calculated on savings in life and abilities rather than dollars. Costs of alternative programs, or of their administration alone, might also be compared without reference to the dollar value of people.

The Winslow-Myrdal exchange has served to point up three needs: (a) greater precision in defining measurements of the cost of sickness, (b) more careful distribution between primary and secondary impacts and effects of health programs, and (c) a more careful formulation of assumptions that underlie alternative economic models (static or dynamic) used in estimating the costs of sickness. The exchange, moreover, has served to provide a broad perspective from which to explore the subject matter of health economics.

\section{Health Economics Defined}

Tentatively defined, health economics is a field of inquiry whose subject matter is the optimum use of resources for the care of the sick and the promotion of health. Its task is to appraise the efficiency of the organization of health services, and to suggest ways of improving this organization.

Promotion of health patently involves more than services of the health professions. It includes food, housing, recreation, and clothing, but, although they contribute importantly to health and wellness, they must be excluded from the scope of health economic studies. Unless they are excluded, the scope of these studies would encompass all economic activities and the special problems of health economics would receive inadequate treatment. While the scope of health economics may be delimited in this way, account must be taken of the competing uses of scarce resources, the impact of economic levels and economic growth on the status of health, and the need for health services.

The allocation of economic resources is generally determined in the market by the preference of consumers for different types of consumer goods and by the preference of workers for different types of work, leisure, and income. Welfare economists have taken these preferences, as expressed in the market, as the guide to optimum use of resources (1416).
But there are a number of reasons why these preferences are not a wholly reliable guide to optimum use of health resources, even when the word optimum is used in this special sense.

First, the consumer would prefer to avoid illness and the purchase of health services. And, as has already been indicated, there are sizable "extra-buyer benefits" in an individual's purchase of medical services. Others in the community benefit from his purchase. Purchases by some consumers, for example, of influenza vaccination during the recent epidemic prevented further spread of the disease. The value of the medical services to each consumer did not depend upon his consumption of medical services alone but upon decisions of his neighbors as well. Those who made no purchases of influenza vaccine also benefited. Thus, the social value of medical services is far larger than the private marginal value. Individual decisions of a consumer are therefore inadequate as an efficient guide to the optimum allocation of resources for health purposes. For these individual decisions undervalue health services, which results in an underproduction of these services.

Second, some health services do not lend themselves to pricing on the market so that society's preference for them cannot be adequately valued on the market. Air and water pollution control measures, fluoridation of water supplies, and mosquito control are examples of these services. Furthermore, the price system for individual services is not applied in all cases: $(a)$ the medically indigent are not excluded from care when they are sick, and $(b)$ public safety and health sometimes require direct provision of health services and the removal of the individual from the community. Public hospital services for the mentally ill and for those with tuberculosis are illustrative of services placed outside the price-market system.

Third, the allocation of health resources is determined by a mixture of private market decisions and administrative decisions. "Administrative decisions" include those decisions made by the government, private nonprofit agencies, and professional organizations. Decisions concerning some health facilities (the building and size of a general hospital, for example) are 
made by voluntary agencies. The Visiting Nurse Association determines the availability of part-time nursing care in many communities. In some places the content and quality of rural health services are determined by the regional organizations associated with medical schools. The principles underlying these administrative decisions and the way in which they influence the allocation of health resources need to be explored.

It may be that the principles underlying public budget decisions are applicable to administrative decisions of voluntary health agencies as well as public agencies. While economists have largely neglected theories of public expenditure in favor of theories of taxation and policy, analysis of governmental budgeting has begun. The Joint Economic Committee of Congress, by its 1957 study of Federal expenditure policy for economic growth and stability, has stimulated the development of principles for determining public budget $\left(1^{\prime} \%, 18\right)$. Review of the work is needed to assess its contribution to our understanding of the optimum allocation of economic resources for health.

Consumer preferences as expressed in the market are one guide to optimum use, even though an incomplete guide. Another thing to look at is the effect of health programs on labor resources and production. Gains in output as a consequence of health services may equal or exceed (in a given period of time) the resources used for health. The number and quality of new manpower resources must be compared with the health manpower used in the provision of services. For example, it would be possible to compare the amount of manpower used in providing health services in the United States with gains in labor force participation resulting from reduced death rates. Reduced death rates in the United States have resulted in a decline in separations from the labor force at all ages up to age 65 . Despite the marked delay in entry into the labor force by young people, and the earlier exit from the labor force by those in the older age groups, the male worker today puts in many more years of work than did his counterpart 50 years ago (19). The problems of cost-benefit measurement have been mentioned in the discussion of the Winslow-Myrdal exchange. The concepts and methods of measurement require extensive further study. Not potential but actual increases in production under prevailing conditions of employment must be measured against the cost of health services in order to determine their relationship to the economic optimum.

One additional aspect of the problem may be mentioned. The economic optimum bears some relation to the amount of health resources required to provide care for all the illnesses in the population. The optimum may be below or above the amount of health services suggested by professional standards. Standards of health resource requirements are familiar to the health practitioners. Professional planning for health services and setting standards are characteristics of the health field. Standards of professional education, requirements for entrance into the health professions, hospital standards, and even in some instances standards of care are determined by professional groups. Moreover, government, by compulsory measures, has enforced standards of public health. For example, vaccination is required as a condition for admission to school, and standards are set for the distribution of milk, for food handlers, and for water supplies.

The National Health Survey is designed to provide data on sickness in the population. In discussing the potential uses of data from such a survey the U.S. National Committee on Vital and Health Statistics indicated that quantitative information would provide a basis for sound evaluations of health facilities, personnel, and programs as well as for a determination of how available resources should be divided among programs (20). In an earlier study, Leo and Jones related sickness in the population to the needed volume of health services and manpower requirements (21).

The subject matter of health economics includes factors that determine price patterns for health services, ways in which the materials, goods, health manpower, and facilities are brought together at the right time and place and in the right proportions to provide health services, and ways in which the different health goods and services are coordinated. The mechanisms by which goods and services are coordinated are "trade" in the market by the consumer's purchases of health goods and services, 
professional codes of performance, and governmental and voluntary agency planning and budget decisions.

Health economics also includes in its subject matter the effects of health services on the size, character, and efficiency of the work force and population. It seeks to gain an understanding of the interaction of levels of living, production, and physical and mental wellness. The health factors which make for work absence, for retirement from work, for labor turnover, for the quality of performance on the job, and for job satisfaction fall within the scope and concern of health economics. The general topics which need to be considered in a comprehensive treatment of the economics of health include the interaction of health services and gross national output, population growth and economic development, and productivity of labor forces; health problems associated with industrial development; the supply of health services; utilization of services and their pricing; and financing of public and nonprofit agency programs.

The scope of inquiry included in the tentative definition of health economics is by no means novel. It is suggested by the work that is going forward in the bureau of medical economics of the American Medical Association, and the bureau of economic research and statistics of the American Dental Association. These organizations have explored the interaction of use and price of health services, health manpower, and facilities and consumer demand. The studies of Eli Ginzberg, Herbert Klarman, and others have increased our understanding of the economics of the hospital system (22). Ginzberg's work has also included an examination of the special economic problems of health manpower and methods of providing care (23, 24). And an increasing number of doctoral dissertations in economics have been concerned with these, or similar problems.

\section{Summary}

The health administrator has usually equated "health economics" with "money questions in the field of health." But, money is not the central problem of health economics. Health economics is concerned with the optimum use of scarce economic resources for the care of the sick and the promotion of health, taking into account competing uses of these resources. The basic problems are of two kinds: the organization of the medical market, and the net yield of investment in people for health.

Consumer preferences are not an adequate guide to the optimum allocation of resources for health. There are a number of reasons why this is so. For one thing, a consumer would prefer to avoid the illnesses which require use of resources for health purposes. For another, his neighbors benetit from the medical services he purchases, for example, "flu shots" during the recent influenza epidemic. Individual decisions undervalue health services, and would result in underproduction of these services unless supplemented by actions of private voluntary agencies and government.

\section{REFERENCES}

(1) U. S. National Health Survey: Health statistics. Preliminary report on volume of dental care, United States, July-September 1957. Public Health Service Pub. No. 584-B2. Washington, D. C., U. S. Government Printing Office, 1958. p. 7.

(2) U. S. National Health Survey: Health statistics. Preliminary report on volume of physician visits, United States, July-September 1957. Public Health Service Pub. No. 584-B1. Washington, D. C., U. S. Government Printing Office, 1958. p. 13.

(3) Marshall, A.: Principles of economics. Ed. 8. London, Macmillan and Co., 1938. (a) p. 764 ; (b) p. 193.

(4) Leibenstein, H.: Economic backwardness and economic development. New York, John Wiley \& Sons, Inc., 1957, ch. 10.

(5) Dublin, L. I., and Lotka, A. J.: The money value of a man. Rev. ed. New York, Ronald Press Co., 1946.

(6) U. S. Department of Labor, Bureau of Labor Statistics: Tables of working life for women. Bull. 1204. Washington, D. C., U. S. Government Printing Office, 1957.

(7) U. S. Department of Labor, Bureau of Labor Statistics: Tables of working life; length of working life for men. Bull. 1001. Washington, D. C., U. S. Government Printing Office, 1950.

(8) Quetelet, quoted in René Sand: The advance to social medicine. London, Staples Press, 1952, p. 584.

(9) Winslow, C.-E. A.: The cost of sickness and the price of health. Monogr. Series No. 7. Geneva, World Health Organization, 1951. (a) p. 9: (b) p. 80 . 
(10) Health is wealth [An abridged version of reference 9]. Geneva, World Health Organization [1952?]

(11) Winslow, C.-E. A.: The economic values of preventive medicine. Chron. World Health Org. 6 : 196, August 1952.

(12) Myrdal, G.: Economic theory and underdeveloped regions. London, Gerald Duckworth and Co., 1957, pp. 16, 17.

(13) Myrdal, G.: Economic aspects of health. Chron. World Health Org. 6 : 211, August 1952.

(14) Baumol, W. J. : Welfare economics and the theory of the State. Cambridge, Harvard University Press, 1952.

(15) Macfie, A. L. : Economic efficiency and social welfare. New York, Oxford University Press, 1943.

(16) Scitovsky, T.: Welfare and competition. Chicago, Richard D. Irwin, Inc., 1951.

(17) U. S. Congress, Joint Economic Committee : Hearings . . . Federal expenditure policy for economic growth and stability. 85th Cong., 1st sess. Washington, D. C., U. S. Government Printing Office, 1958.

(18) U. S. Congress, Joint Economic Committee : Federal expenditure policy for economic growth and stability. Joint committee print. 85th Cong., 1st sess. Washington, D. C., U. S. Government Printing Office, 1957.

(19) Wolfbein, S. L.: The length of working life. Paper presented at Fourth International Gerontological Congress, Merano, Italy, July 1957. Washington, D. C., U. S. Bureau of Labor Statistics, 1957.

(20) U. S. National Committee on Vital and Health Statistics: Proposal for collection of data on illness and impairments in the United States; a report of the subcommitee on national morbidity survey. PHS Pub. No. 333. Washington, D. C., U. S. Government Printing Office, 1953.

(21) Lee, R. I., and Jones, L. W.: The fundamentals of good medical care. Chicago, University of Chicago Press, 1933.

(22) National Planning Association: Good health is good business; a summary of a technical study. Planning Pamphlets No. 62. Washington, D. C., 1948.

(23) Ginzberg, E.: What every economist should know about health and medicine. Am. Ec. Rev. 44: 104-119, March 1954.

(24) Ginzberg, E. : Health, medicine, and economic welfare. J. Mount Sinai Hospital 19: 734-743, March-April 1953.

\section{Report of International Association of Gerontology}

A conference of the European section of the Social Science Research Committee, International Association of Gerontology, held in Copenhagen, Denmark, in October 1956, discussed pensions, assistance, and levels of living, work and retirement, and family and institutional care. The conference recommended that, for purposes of comparison, data be collected in various countries on old people living alone or with relatives, those living in institutions and nonprivate households such as hotels, those who have surviving children, and those who are bedridden, housebound, or limited in movement.

Speakers from the United Kingdom, Italy, Denmark, and the Netherlands described and discussed surveys of income, budgets, living conditions, family relationships, pensions and retirement, research on employment, causes of institutionalization, costs of institutional versus home care, and sociomedical surveys.

The proceedings, entitled "The Need for Cross-National Surveys of Old Age," are available from the Division of Gerontology, University of Michigan, 1510 Rackham Building, Ann Arbor, Mich. 


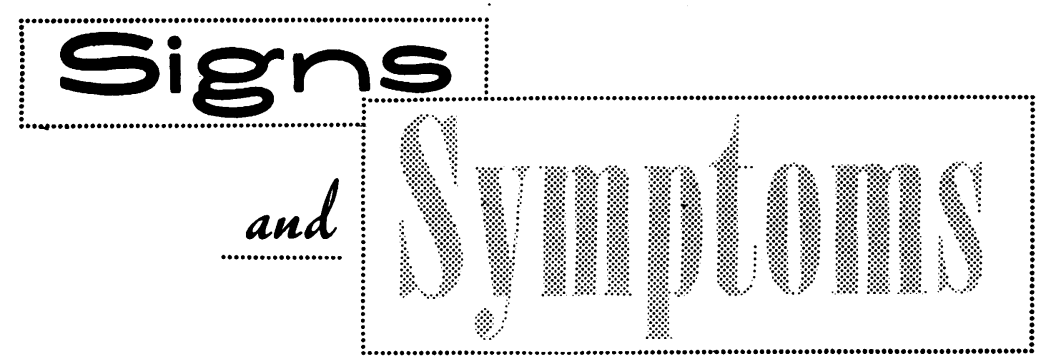

With this issue, a new department, Signs and Symptoms, is opened. Its main purpose is to provide a setting for what Dr. Joseph W. Mountin once called gems of public health practice. In addition to rare gems, it will give brief notice to other events or activities presumably of interest to readers. The doings of local and State health organizations will be the prime, but not the exclusive, focus of this department, especially if they indicate an important trend or some outstanding development or achievement. Contributions are welcomed.

\section{Directory of Services}

A directory describing all services in Greater Cleveland, Ohio, for care of the chronically ill has been published recently by the Cleveland Academy of Medicine and the Welfare Federation of Cleveland.

Intended as a reference for doctors and staff members of health and welfare agencies, the 118-page book lists about 200 different agencies.

In addition to medical facilities, the services described include nursing and rehabilitative, educational, financial, and casework assistance. Special sections deal with the treatment of chronically ill children, older persons, and veterans.

Information about each agency includes: services, eligibility requirements, area served, fees, hours, and referral procedures.

The directory has been distributed to some 2,800 doctors in the Cleveland area.

\section{Traveling Clinic}

Rural arthritic victims in Westchester County, N. Y., are being treated in their homes by therapists. The New York State Chapter of the Arthritis and Rheumatism Foundation sends therapists to patients unable to leave their homes or unable to travel to distant clinics.

The patients' private physicians approved the program and consulta- tion with them has resulted in the training of visiting nurses in rehabilitation and the enlistment of help from social workers, nutritionists, and others.

By the beginning of June 1958, nearly 100 patients had been visited and 38 cases had been closed.

\section{Pay for Patients}

In a pilot program 25 mental patients have been working for pay at the New York State hospital in Central Islip.

Patients work at small handerafts or such simple tasks as sewing buttons on cards.

Dr. Francis J. O'Neill, director of the hospital, reports that the patients are not approaching financial independence, but he feels the work advances rehabilitation.

\section{Keeping Current}

Responsibility for keeping current with public health literature is managed by the Saanich and South Vancouver Island Health Unit, Victoria, British Columbia, by giving each staff member an opportunity to report at a regular meeting on reading he has done. ior sanitary inspector, reports that staff members give the title, author, and source; a brief statement of the author's purpose; a comment on
H. George Henderson-Watts, sen- the noteworthy aspects of the paper; and the conclusions of the author and reviewer, if any. The paper itself is not read to the staff as a rule: the purpose of the review is simply to inform the staff and to encourage reading in pertinent fields. Reviews ordinarily are limited to 5-10 minutes. Time is also allowed for questions and discussions.

Periodicals, bulletins, and magazines are assigned on a 6-month or yearly basis.

Staff members are encouraged to read in detail the papers they review, to mark important points, and to read them a second time before offering their review.

\section{Home Safety}

The final report of the California Home Safety Project covering the years 1953-57 has been issued by the California Department of Public Health. The 165-page report reviews the home accident problem in California and outlines a program of State and local health department activities. It emphasizes the epidemiological approach to accident prevention. Distribution of the report is limited.

\section{Hearing Tests}

Audiometric tests for parents help them to understand corrective therapy and sound range limitations of children with hearing losses, the Alaska Department of Health reports.

The tests, offered during National Hearing Month in May 1958, were available to 5 communities; 196 adults were tested.

\section{Glaucoma}

In the summer of 1957 funds from the Public Health Service enabled the District of Columbia to begin examining residents over age 40 for glaucoma provided they were not under care of an eye doctor. By the end of May 1958, 3,866 patients had been examined and 27 cases of glaucoma verified. An additional 238 patients were under observation. 